\title{
Daily and seasonal movements of Cape Cod gray seals vary with predation risk
}

\author{
Jerry H. Moxley ${ }^{1,4, *}$, Gregory Skomal ${ }^{2}$, John Chisholm², Patrick Halpin ${ }^{1,3}$, \\ David W. Johnston ${ }^{1}$
}

${ }^{1}$ Division of Marine Science and Conservation, Nicholas School of the Environment, Duke University Marine Lab, Beaufort, NC 28516, USA

${ }^{2}$ Massachusetts Division of Marine Fisheries, New Bedford, MA 02744, USA

${ }^{3}$ Division of Marine Science and Conservation, Nicholas School of the Environment, Duke University, Durham, NC 27708, USA

${ }^{4}$ Conservation Research, Monterey Bay Aquarium, Monterey, CA 93940, USA

\begin{abstract}
White sharks Carcharodon carcharias and gray seals Halichoerus grypus are reestablishing their ecological roles within the Northwestern Atlantic Ocean, presenting an opportunity to understand gray seal movement and at-sea behavior under predation risk. As with other shark-seal hotspots, movements to and from terrestrial haul outs can be risky for gray seals, thereby eliciting antipredator strategies. We investigated the movement and coastal behavior of gray seals on Cape Cod (USA) in relation to seasonal and diel changes in white shark activity. Analyzing 412 trips to sea by 8 seals and more than 25000 acoustic detections from 23 individual white sharks, we observed seasonally homogeneous movements in seal behavior during months with greater shark presence. During riskier months, seal behavior manifested in near-exclusive nocturnal foraging, reduced offshore ranging, and limited at-sea activity. On these nocturnal trips to sea, seals returning to haul outs tended to avoid daybreak and traversed during diel minima in shark activity. However, seals tended to depart haul outs at dusk when shark presence was maximal. As conservation efforts succeed in rebuilding depleted populations of coastal predators, studying re-emerging predator-prey interactions can enhance our understanding about the drivers of movement and behavior.
\end{abstract}

KEY WORDS: Food-safety tradeoff · Gray seal · Halichoerus grypus $\cdot$ White shark $\cdot$ Carcharodon carcharias $\cdot$ Predation risk $\cdot$ Behavioral ecology

\section{INTRODUCTION}

Effective risk mitigation underlies the success and safety of animal movement behavior (Lima \& Dill 1990, Laundré et al. 2014). Generally, animals are expected to invest in heightened vigilance and tenacity in the presence of predators (Creel 2011). Additionally, social animals often use group formation to counter predation pressure (Caro 2005, de Vos \& O'Riain 2013). To reduce risk further, animals may also adopt avoidance strategies and adjust activity budgets (Creel et al. 2008).

Behavioral strategies for predator avoidance are constrained by an animal's need to access other resources

${ }^{*}$ Corresponding author: jerry.moxley@gmail.com in foraging, resting, or other habitats (Creel 2011). Efficacy of avoidance can be modulated by dynamics and characteristics of these critical needs, particularly if predators can cue off predictable behaviors for dependable foraging opportunities. Central place movement is a prevalent movement paradigm for many marine predators, including seabirds and seals (Orians \& Pearson 1979, Olsson et al. 2008). The concentration of encounter rates and predation risk within this arena could favor alternate and/or additional avoidance strategies (Le Boeuf \& Crocker 1996, de Vos et al. 2015, Jewell et al. 2019).

Temporally, animals can manage predation risk in the arena near central places by allocating move-

(C) The authors 2020. Open Access under Creative Commons by Attribution Licence. Use, distribution and reproduction are unrestricted. Authors and original publication must be credited. 
ments and activity temporally (Lima \& Bednekoff 1999, Ferrari \& Chivers 2009). Indiscriminate temporal avoidance incurs the least risk, but also sacrifices foraging opportunities. Instead, risky foraging activity by animals may be linked to duration and/or frequency of risk pulses that, in turn, affect the opportunity costs of missed foraging for the prey animal (Lima \& Bednekoff 1999, Bednekoff \& Lima 2011). Dynamic approaches to ubiquitous food-safety tradeoffs are necessary for animals to forage safely and effectively (Ferrari \& Chivers 2009, Trussell et al. 2011).

Seals exhibit central place movement behavior, alternating between haul out habitats used primarily for resting and at-sea habitats where they forage (Reynolds et al. 1999). Sharks are known to congregate and patrol near seal haul outs (Martin et al. 2005, Fallows et al. 2012). Resulting risk scenarios may induce food-safety tradeoffs (Brown \& Kotler 2004) that can underlie seal movement decisions about when, where, and how to leave colonies (Le Boeuf \& Crocker 1996).

To avoid shark predation, seals must traverse nearshore marine habitats adjacent to terrestrial refuges where white sharks Carcharodon carcharias hunt (Klimley et al. 1996, 2001, Martin et al. 2005, Laroche et al. 2008). Studies of shark foraging behavior show that attacks occur in relatively shallow water (5$50 \mathrm{~m})$ and near shore ( $<400 \mathrm{~m}$; Fallows et al. 2012). Ambush-style attacks are common, with sharks using visual backlighting, rapid approaches, and powerful jaws to debilitate and capture prey (Tricas \& McCosker 1984). Consumption of juvenile seals is most commonly observed, but all age-classes are targeted (Laroche et al. 2008, Brown et al. 2010, Fallows et al. 2012). Dawn and dusk periods are highlighted for increased frequency of attacks, although predations occur throughout the day and occasionally at night (Fallows et al. 2012).

Populations of gray seals Halichoerus grypus and white sharks in the Northwest Atlantic are recovering from depletion and are re-establishing ecological linkages (Curtis et al. 2014, Moxley et al. 2017, Skomal et al. 2017, Wood et al. 2020). Gray seals are social pinnipeds that aggregate at shared terrestrial haul outs in between single- and multi-day movements offshore (Breed et al. 2009). Gray seals feed primarily on demersal fishes (Beck et al. 2007, Breed et al. 2009), some of which are commercially valuable (Trzcinski et al. 2006, O'Boyle \& Sinclair 2012, Hammill \& Stenson 2014). In the past, perceptions of competition with fisheries motivated hunting and statefunded bounty programs that greatly reduced gray seal populations in the Northwest Atlantic (Lelli et al. 2009), including extirpation from the US coastline (Wood et al. 2020). Following conservation efforts, gray seal colonies in the Northwest Atlantic are recovering (Hammill et al. 2017, Moxley et al. 2017, Wood et al. 2020), providing a growing prey base for Atlantic white sharks in some locations (Skomal et al. 2012). Atlantic white sharks overwinter off the southeastern US and the Gulf of Mexico, or in deep (>50 m) pelagic habitat (Skomal et al. 2017). In summer months, sharks migrate northwards and move into coastal waters (Curtis et al. 2014, Skomal et al. 2017), where they are now observed reliably near gray seal haul outs (Skomal et al. 2012, 2017).

In this study, we examined how GPS-tagged gray seals allocated at-sea activity and structured foraging trips in relation to seasonal and diel periodicity in the presence and nearshore activity of white sharks tagged acoustically. We anticipated that seals would limit risk when accessing foraging opportunities by avoiding risky areas around haul outs during heightened shark activity. In this way, we hypothesized that the frequency and timing of coastal traverses in gray seals would covary with nearshore activity of white sharks. We also investigated relationships between coastal movement patterns and crepuscular light dynamics to understand potential seal behavioral response to visual predation tactics of sharks. If seals were countering visual detection, we hypothesized that traversing behavior would be more common during crepuscular and nocturnal periods with low or no ambient light. Thus in examining coastal movement behavior during these risky traverses, we investigated how seals modulate movement behavior in response to the predation risk imposed by white shark presence and activity.

\section{MATERIALS AND METHODS}

\subsection{Data collection}

Movement behavior of 8 individual gray seals was monitored for 2-9 mo by GPS/GSMR telemetry tags (Global System for Mobile Communications/ General Packet 145 Radio System, SMRU Instrumentation; www.smru.st-andrews.ac.uk/Instrumentation/ Overview/; $10 \mathrm{~cm} \times 17 \mathrm{~cm} \times 4 \mathrm{~cm}, 370 \mathrm{~g}$ in air). Tags were deployed primarily in June 2013 on individual seals ( $\mathrm{n}=7$, including 3 males aged 3-7 $\mathrm{yr}$ old and 4 females aged 4-12 yr old; age was determined through dental annuli, Bernt et al. 1996). Seals were live-caught by beach seine at a tidally-dependent 
sandbar in Chatham Harbor, MA (41.67 $\left.\mathrm{N}, 69.95^{\circ} \mathrm{W}\right)$. One tag was deployed opportunistically on a rehabilitated individual ( $\mathrm{n}=1$ juvenile male, September 2012). Tags were attached to the animals' fur using a mix of 2-part epoxy and mesh webbing. A total of 35577 locational fixes (median $=5387.5$ ind $^{-1}$, range 991-8972, $\sigma=2944.9$ ) were recorded with Fastloc ${ }^{\circledR}$ GPS technology (median residual $=7.8 \mathrm{~m}, \sigma=0.2 \mathrm{~m}$ ), with a median of 22.5 geolocation fixes ind. ${ }^{-1} \mathrm{~d}^{-1}$ (range 3.56-31.93, $\sigma=9.6$ ) and most individuals transmitting at least 1 location $\mathrm{h}^{-1}$.

\subsection{Seal space use and movement behavior}

For fine-scale movement analyses, unfiltered relocation data were fit with a continuous-time correlated random walk and movement steps standardized evenly every $30 \mathrm{~min}$ (Johnson et al. 2008). Consistent with other studies, trips to sea were identified by sequential movements $>2 \mathrm{~km}$ from the shoreline (McConnell et al. 1999, Breed et al. 2009). Coastal traversing behavior was appended as the locations within $2 \mathrm{~km}$ of shore immediately preceding and following a trip to sea. At-sea locations nearest to the coastline (i.e. harbor, backwater, and land positions masked) during each traverse were identified as the trip's initiation or termination, respectively. This method identified inlet crossings as the initiation and termination of foraging trips as animals depart from or arrive at inshore habitats. Foraging trips were considered independent when separated by haul-out events, inferred from the tag's wet/dry sensor being continuously dry for 10 min. Fitting of movement models, trip identification, and all further statistical analyses were done within R (version 3.3.3).

Intra-annual space use patterns were characterized using a robust product kernel method that calculates utilization distributions (UDs) across temporal dimensions (Keating \& Cherry 2009; spatial bandwidth $=1000 \mathrm{~m}$, available in $\mathrm{R}$ package 'adehabitat' v.0.4.15, Calenge 2006). An 8 d window representing median trip duration reported in the literature (Breed et al. 2009) was used as the temporal smoothing parameter. Preliminary sensitivity analyses assessed patterns with windows between 3 and $30 \mathrm{~d}$, but found little difference in overarching patterns detected. UDs $\left(\mathrm{km}^{2}\right)$ were summarized for $95 \%$ isopleths. Simple segmented regression was used to identify structural change points within the intra-annual pattern (see Section 1 in the Supplement at www.int-res.com/articles/suppl/m644p215 _supp.pdf), minimizing deviance within a sensitivity analysis to identify the breakpoint. The sensitivity analysis calculated regressions iteratively with breakpoints between 1 October and 1 January (see Fig. S1 in Section 1 of the Supplement), using the Chow test to calculate significance of the data's structural change (Chow 1960). Seasonal behavior was divided on the basis of this breakpoint. Interindividual variability in home range estimates was assessed with a clustering analysis, using the partitioning around $k$-medoids method (available in $\mathrm{R}$ package 'fpc' v. 2.2-3; Henning 2020). k-medoids, over $k$-means, is a method is noted for robustness in small studies (see Section 1 in the Supplement). We analyzed clustering within the data, tested sensitivity by varying the number of clusters between $k=2$ and 5 total, and used Manhattan distance to determine the optimal value of $k$. Cluster dissimilarity and diameter, each a measure of the spread or variability observed in the cluster, were assessed for an indirect proxy of behavioral variability (see Section 1 in the Supplement).

Trip metrics (distance traveled, duration, and maximum offshore range) were calculated for each foraging trip $(\mathrm{n}=412)$ and summarized seasonally for individuals and by sex. Warm and cold seasons were defined by structurally distinct space use patterns during the months of June to October and November to March, respectively. Mixed effect rank-regression models (R package 'nlme' v. 3.1-131, Pinheiro et al. 2017) were used to test if trip metrics differed by season and/or sex effects (Table S3, Fig. S3 in Section 2 in the Supplement). Individual tagged seals were used as random effects, and trip metrics transformed into their ordinal rank (see Section 2 in the Supplement). ANOVA tested the effect of increasing model complexity on overall predictive performance (Table S3). Circular statistics (available in R package 'circular' v. 0.4-93; Lund \& Agostinelli 2017) were used to analyze distributions of temporal variables (e.g. time of day of trip initiation/termination). The Rayleigh test was used to confirm deviations from circular uniformity, where mean direction $(\theta)$ was analogous to the distribution's central moment, and mean resultant length $(\bar{R})$ was analogous to the concentration around that central moment (Pewsey et al. 2013). The complement of rho (i.e. $1-\bar{R}$ was used as the sample's circular variance, and thus values of $\bar{R}$ approaching 1 indicate that data were closely clustered around the mean direction. The Wallraff nonparametric test for circular homoscedasticity was used to test if trip initiation and termination events in different seasons were drawn from distributions with a common concentration (Pewsey et al. 2013). 


\subsection{Shark activity cycles}

Activity cycles of white sharks were quantified from 2 sources: (1) detections of tagged white sharks at acoustic buoys near Cape Cod seal colonies and (2) observations of white sharks from seasonal field surveys (Skomal et al. 2017). During the summers of 2010-2014, 44 white sharks (2.4-5.3 m total length) were tagged with acoustic transmitters (model V16, Vemco) as part of an ongoing movement ecology study. Tagging took place on free-swimming sharks found adjacent to gray seal haul outs on the outer coast of Cape Cod (Skomal et al. 2017). During years of gray seal tracking, white shark activity was monitored with an array of 16 acoustic receivers (model VR2W, Vemco; detection range $\sim 100-300 \mathrm{~m}$ ). This acoustic array was deployed annually in late May and retrieved mid-December ( 203-205 detection days in each year; Table S5 in Section 3 in the Supplement) to maximize shark detection along a contiguous stretch of Cape Cod coastline. Receivers were placed in 4.5-7.5 m depth of water near seal haul outs to maximize white shark detection. Acoustic data were filtered for false detections based on the criteria outlined by Pincock (2012) using the manufacturer's software (VUE, https:// vemco.com/products/vue-software/).

Diel shark activity was summarized hourly for inshore monitoring receivers. Cumulative distribution functions quantified the seasonal presence of white sharks within the Cape Cod region. Furthermore, expected days between repeat detections of an individual on another day were calculated from pairwise differences in all detections for that individual within a sampling year. Diel activity was reported as the total frequency of detections observed within an hour, as well as the mean individual detection rate for each hour of the day, root standardized for the number of days the individual was detected during that hour. To account for light effects on shark-seal interactions, changes in ambient environmental light were inferred from astronomical positions of the sun in relation to the horizon. Solar elevation angles were calculated based on the time of day for each trip's initiation and termination. Diurnal/nocturnal transitions were defined by astronomical twilight, when the solar elevation angle is $18^{\circ}$ below the horizon. Twilight periods (i.e. dawn and dusk) were defined by the period between astronomical twilight (solar elevation $=-18^{\circ}$ ) and sunrise $/$ sunset $\left(\right.$ solar elevation $=0^{\circ}$ ). Solar elevation angles as well as local time of sunrise and sunset were calculated using NOAA algorithms available in R (Lewin-Koh \& Bivand 2011).

\section{RESULTS}

\subsection{Space use patterns in seals}

Tagged seals exhibited distinct seasonal space patterns, abruptly and rapidly expanding the area used during colder months (Table 1, Fig. 1). The most constricted space use occurred in August (median $16.0 \mathrm{~km}^{2}$; Table 1), in stark contrast to post-breeding behavior in January, when median area used was $354.6 \mathrm{~km}^{2}$ (Table 1). Across months, divergent trends were apparent: initially in summer months, behavior was concentrated nearshore in small, overlapping UDs (Figs. 1 \& 2). During this time, space use requirements were apparently invariant (Fig. 1) and movements focused on habitats adjacent to haul outs (Fig. 2a). In subsequent months, both pre- and postbreeding, individual space use patterns expanded abruptly, resulting in the use of larger and broader areas (Table 1, Figs. 1 \& 2b). Structural change in the temporal effect on space used identified a highly significant breakpoint (Chow test, $f=9.43, \mathrm{p}<0.00001$; Table S1, Fig. S1) near 5 November that partitioned spatial movement behavior into warm (June to 5 November) and cold seasons (5 November to March; see Section 2 in the Supplement).

Spatial clustering with $k$-medoids independently confirmed the lack of heterogeneity between individuals' spatial behavior in the warm season (Fig. S2 in Section 1 in the Supplement), and $k$-medoids identified 3 size-structured clusters: small (cluster 1), moderate (cluster 2), and large (cluster 3 ) home range estimates (Table S2). The small home range cluster encapsulated $96 \%$ of home ranges prior to the break-

Table 1. Monthly space use $\left(\mathrm{km}^{2}\right)$ estimates for tagged gray seals

\begin{tabular}{|lcrcrc|}
\hline Month & Active tags & Mean & Median & SD & \multicolumn{1}{c|}{ Range } \\
\hline Jun & 6 & 47.706 & 51.088 & 31.931 & $9.722-105.639$ \\
Jul & 6 & 34.745 & 37.348 & 22.904 & $5.322-74.413$ \\
Aug & 5 & 18.754 & 16.017 & 13.693 & $3.019-38.853$ \\
Sep & 6 & 35.579 & 23.121 & 44.064 & $2.446-179.578$ \\
Oct & 6 & 42.434 & 19.01 & 47.907 & $1.823-167.357$ \\
Nov & 6 & 141.483 & 79.631 & 145.868 & $7.435-451.986$ \\
Dec & 6 & 236.927 & 120.191 & 244.017 & $2.23-791.209$ \\
Jan & 6 & 373.328 & 354.609 & 138.758 & $164.774-642.771$ \\
Feb & 5 & 359.455 & 245.272 & 226.254 & $155.084-947.826$ \\
Mar & 4 & 298.448 & 227.28 & 140.141 & $155.31-506.077$ \\
& & & & & \\
\hline
\end{tabular}




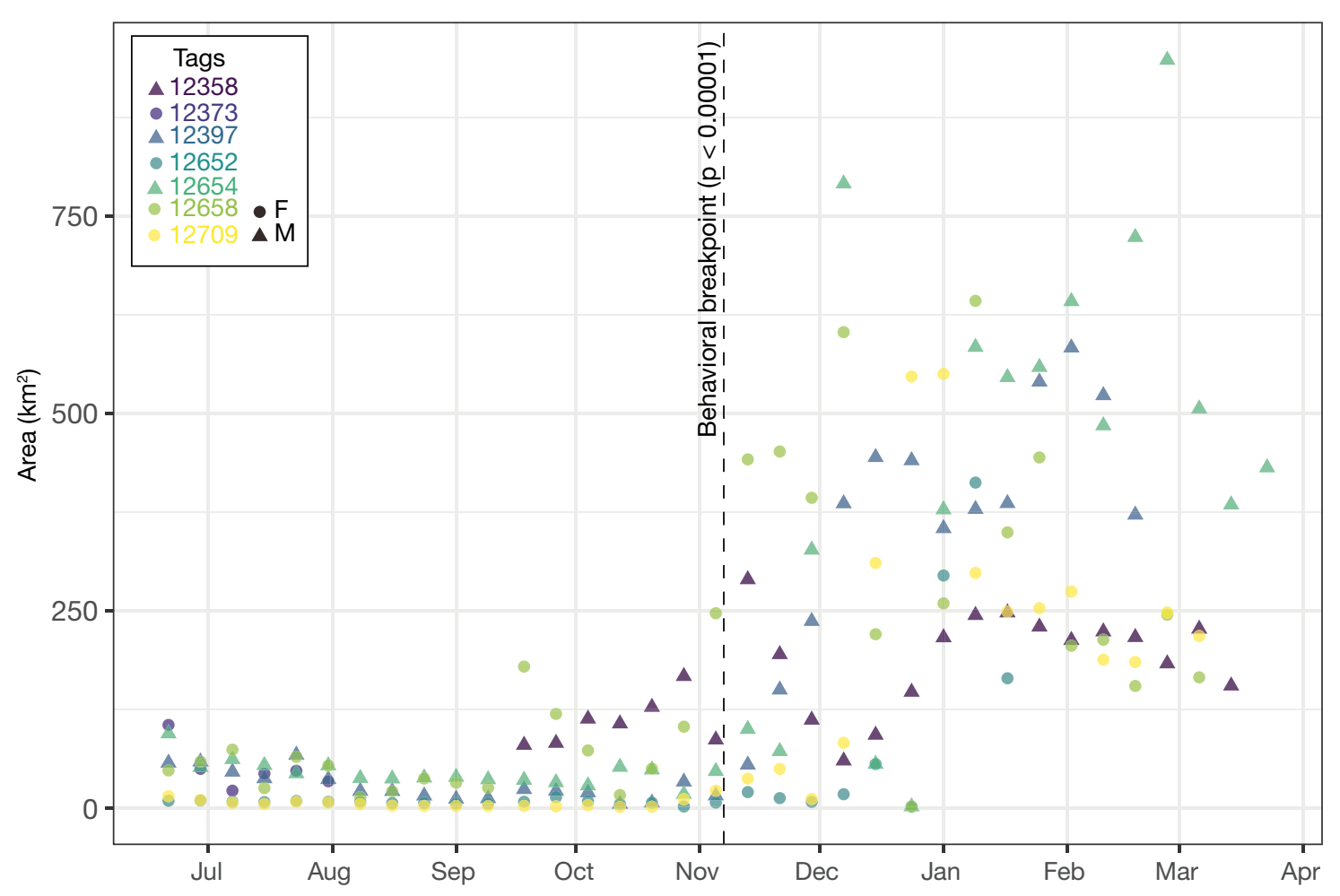

Fig. 1. Divergent trends in space use by tagged seals, emphasizing 2 seasonal phases. Initially, animals concentrated within small, overlapping areas that were relatively invariant over time. Subsequent space use rapidly expanded into larger areas that were further offshore and more individually variable. The breakpoint distinguishing these trends (vertical dashed line) was highly significant (Chow test, $f=9.43, \mathrm{p}<0.000001$ ). The distinct periods (warm: tag on/June to 5 November; cold: 5 November to March/tag off) form the quantitative division for understanding 2 seasons of movement behavior in tagged seals on Cape Cod. M: male, F: female

point (99 of 103 area estimates), validating the significance of the seasonal breakpoint. This cluster also represented a disproportionate number of estimates (62\% overall; 118 of 188 total area estimates; Table $\mathrm{S} 2)$, yet exhibited the least dissimilarity $(0.13$, in comparison to 0.22 and 0.56 for moderate and large clusters) and shortest diameter (0.63, compared to 1.18 and 3.15 for moderate and large clusters, respectively; Table S2). Both methods pointed to a seasonal partition in seal behavior, with underlying shifts from low individual variability within small, overlapping home ranges to an abrupt expansion in space used and individual variability observed (Figs. 1 \& 2).

\subsection{Trip analysis of seal movements}

Individual trips exhibited stark differences in duration and distance traveled between warm (June to October) and cold (November to March) months (Table 2, Fig. 2), but were similar amongst individuals and across sexes in summer (Fig. S3). On average, these warm-month trips lasted between 7.2 and
$9.6 \mathrm{~h}$, covered 15 to $18 \mathrm{~km}$ in distance traveled, and remained overwhelmingly within $12 \mathrm{~km}$ of shore (Table 2). Using the tagged individual as a random effect, the fit of models testing seasonal differences (ANOVAs of rank regression with mixed effects; Table S3) did not improve when sex was incorporated. However, low sample sizes across sex limited the power of detecting true sex differences. The best fitting model found that duration and maximum distance traveled offshore best predicted the season within which the trip occurred (AIC $=259.48, \mathrm{p}<$ 0.0145 ; Table S3). As with space use, greater individual variability emerged in trips during cold months and differences between sex were greater (Table 2 , Fig. S3). Typical trips during cold months lasted between 1.8 and $3.8 \mathrm{~d}$, traveling $81.7-191.3 \mathrm{~km}$ and swimming up to $40 \mathrm{~km}$ from shore (Table 2).

\subsection{Diel cycles in seal trips}

Diel timing for the initiation and termination of seal foraging trips from beach haul outs showed clear 

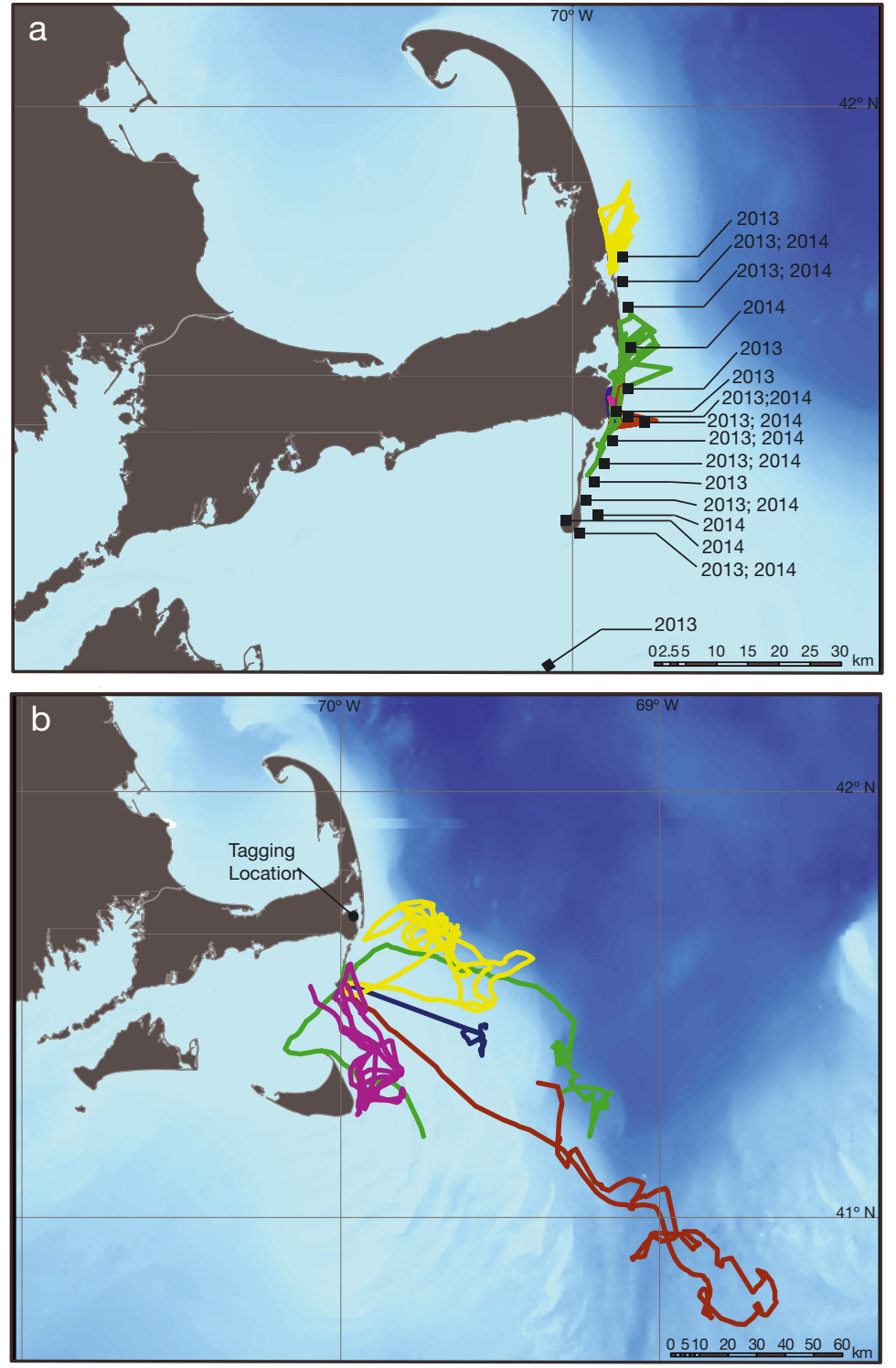

Fig. 2. Typical $8 \mathrm{~d}$ movement patterns of seals across 2 seasons for tagged individuals (track color): (a) June to October, (b) November to March. In warm summer months, seals conducted overnight trips and exhibited concentrated use of nearshore habitats less than $12 \mathrm{~km}$ from haul outs. Winter movement in cold months (b) was characterized by long foraging trips over multiple days to offshore habitats. Acoustic receivers deployed to monitor tagged white sharks are shown in (a) as black squares and labeled by the sampling season active during the study period. All maps created in ESRI ArcMap 10.3 (http://desktop. arcgis.com/en/) by J. Moxley, using GEBCO bathymetry (blue scale)

Between June and Oct, trips departed the coast predominantly between 19:00 and 19:30 h (mean $\bar{\theta} \pm 95 \%$ CI $=-1.21 \pm 0.06$ radians, $\sigma=0.66$; Rayleigh test: $Z=0.8035$, $\mathrm{p}<0.0001$; Fig. 3a) with low temporal variability (mean resultant length, $\bar{R}=0.83 \pm 0.06$, $\mathrm{p}<0.001$; Fig. 3a). Conversely in colder months, seals initiated trips more uniformly throughout the day, with a weaker mean departure vector and larger standard deviation (mean resultant length, $\bar{R}=0.18 \pm 0.10$, $\mathrm{p}<0.003$; mean $\bar{\theta} \pm 95 \% \mathrm{CI}=-1.46$ radians, $\sigma=18.40$; Rayleigh test: $Z=0.1838, \mathrm{p}<0.003$; Fig. 3c).

Upon return from trips, diel patterns in the timing of trip terminations exhibited similar seasonal dissipation (Fig. 3b,d). In warm months, trip terminations clustered around a strong mean vector (mean resultant vector length, $\bar{R}=0.7814 \pm 0.0517$, p $<0.001$; Fig. 3b) between 03:00 and 03:30 h local time (mean $\bar{\theta} \pm 95 \% \mathrm{CI}=0.84 \pm 0.77$ radians, $\sigma=0.70$; Rayleigh test: $Z=0.782, \mathrm{p}<0.001$; Fig. 3b). Again, trips in colder months terminated more uniformly throughout the day (Fig. 3d), with a weaker mean arrival vector and high variability (mean resultant length, $\bar{R}=$ $0.1757 \pm 0.1044, \mathrm{p}<0.003$; mean $\bar{\theta} \pm 95 \%$ $\mathrm{CI}=2.40 \pm 1.46, \sigma=2.29$; Rayleigh test: $Z=$ 0.0734, p $<0.4085$; Fig. 3d).

\subsection{Crepuscular behavior of seals}

Strong warm-season trends in the nocturnal behavior and crepuscular use also dissipated during colder months (Figs. 3 \& 4). In warm months, seals selected crepuscular hours for the initiation and termination of trips to sea (Fig. 4). Crepuscular selection differed by trip segment in warm months, with $92.5 \%$ of trip initiations $(\mathrm{n}=245)$ occurring most closely to sunset and $87.9 \%$ of terminations ( $\mathrm{n}=245$ ) occurring most closely to sunrise. In subsequent cold months, trips ( $n=167$ ) were not aligned with sunsets and

seasonal patterns (Fig. 3). Warm-month trips (Fig. 2a) predominantly featured nocturnal behavior that was consistent among all tagged individuals (Fig. 3a,b). At-sea foraging behavior in colder months (Fig. 2b) occurred during all hours of the day, exhibiting greater individual variability and no discernible diel pattern (Fig. 3c,d). sunrises, with only $59.9 \%$ beginning nearer to sunset and $51.8 \%$ ending closer to sunrise.

Additionally, coastal traverses in warm months exploited dusk's darkening twilight differently than the brightening during dawn twilight (Fig. 4). When leaving the coast, foraging movements began at or following sunset as light waned (Fig. 4a). Following a 
Table 2. Tagging summaries and seasonal trip metrics, including distance, duration, and distance offshore, by individual gray seals as well as by sex. Malfx: equipment malfunction; NA: not applicable

\begin{tabular}{|c|c|c|c|c|c|c|c|c|c|c|c|}
\hline \multirow[t]{2}{*}{ Sex } & \multirow{2}{*}{ Age class } & \multirow{2}{*}{$\begin{array}{c}\text { Age } \\
\text { (yr) }\end{array}$} & \multirow[t]{2}{*}{ Tag } & \multirow{2}{*}{ Season } & \multirow{2}{*}{$\begin{array}{c}\text { Trips } \\
\mathrm{n}\end{array}$} & \multicolumn{2}{|c|}{ Distance $(\mathrm{km})$} & \multicolumn{2}{|c|}{ Duration (d) } & \multicolumn{2}{|c|}{ Distance offshore $(\mathrm{km})$} \\
\hline & & & & & & $\mu$ & $\sigma$ & $\mu$ & $\sigma$ & $\mu$ & $\sigma$ \\
\hline \multirow[t]{2}{*}{ M } & $\mathrm{A}$ & 4 & 397 & Warm & 40 & 18.68 & 7.56 & 0.39 & 0.10 & 7.35 & 3.23 \\
\hline & & & & Cold & 22 & 189.06 & 221.86 & 3.49 & 3.95 & 38.98 & 43.91 \\
\hline \multirow[t]{2}{*}{ M } & $\mathrm{A}$ & 7 & 654 & Warm & 70 & 16.24 & 4.10 & 0.31 & 0.08 & 5.30 & 1.32 \\
\hline & & & & Cold & 13 & 230.76 & 449.39 & 4.54 & 8.75 & 50.77 & 91.93 \\
\hline \multirow[t]{2}{*}{ M } & SA & 3 & 646 & Warm & 13 & 14.52 & 5.52 & 0.30 & 0.07 & 4.64 & 1.72 \\
\hline & & & & Cold & Malfx & NA & NA & NA & NA & NA & NA \\
\hline \multirow[t]{2}{*}{ M } & $\mathrm{J}$ & NA & 358 & Warm & 25 & 29.21 & 40.78 & 0.96 & 1.12 & 6.91 & 5.77 \\
\hline & & & & Cold & 31 & 176.38 & 230.43 & 3.63 & 4.08 & 43.35 & 60.69 \\
\hline \multirow[t]{2}{*}{$\mathrm{F}$} & A & 6 & 658 & Warm & 58 & 15.08 & 8.69 & 0.36 & 0.12 & 4.77 & 2.67 \\
\hline & & & & Cold & 32 & 128.42 & 155.69 & 2.78 & 2.90 & 24.98 & 20.14 \\
\hline \multirow[t]{2}{*}{ F } & $\mathrm{A}$ & 12 & 709 & Warm & 0 & NA & NA & NA & NA & NA & NA \\
\hline & & & & Cold & 55 & 57.87 & 42.94 & 1.21 & 0.89 & 11.36 & 4.52 \\
\hline \multirow[t]{2}{*}{ F } & A & 11 & 652 & Warm & 17 & 15.73 & 2.84 & 0.22 & 0.03 & 5.68 & 1.30 \\
\hline & & & & Cold & 13 & 67.55 & 83.63 & 1.72 & 2.21 & 17.26 & 16.79 \\
\hline \multirow[t]{2}{*}{$\mathrm{F}$} & $\mathrm{A}$ & 4 & 373 & Warm & 22 & 16.15 & 8.28 & 0.30 & 0.10 & 5.32 & 2.88 \\
\hline & & & & Cold & Dead & NA & NA & NA & NA & NA & NA \\
\hline \multirow{2}{*}{\multicolumn{2}{|c|}{ All males }} & & & Warm & 148 & $18.94 \pm 2.88$ & 17.90 & $0.44 \pm 0.08$ & 0.52 & $6.07 \pm 0.52$ & 3.21 \\
\hline & & & & Cold & 67 & $191.31 \pm 67.43$ & 278.48 & $3.76 \pm 1.25$ & 5.20 & $43.35 \pm 15.07$ & 62.46 \\
\hline \multirow{2}{*}{\multicolumn{2}{|c|}{ All females }} & & & Warm & 97 & $15.43 \pm 1.56$ & 7.84 & $0.32 \pm 0.02$ & 0.11 & $5.06 \pm 0.51$ & 2.54 \\
\hline & & & & Cold & 100 & $81.70 \pm 20.08$ & 102.42 & $1.78 \pm 0.40$ & 2.04 & $16.49 \pm 2.84$ & 14.50 \\
\hline
\end{tabular}

night at sea, however, seals returned during nocturnal darkness in greater proportions than when heading to sea (Fig. 4b). Rather than centering near sunrise, trip terminations coincided closely with astronomical twilight (solar elevation angle $=18^{\circ}$ below horizon; Fig. 4b) that marks the interface between twilight and dark night.

\subsection{Coastal visitation of sharks}

Seasonal overlap of tagged gray seals with the Northwest Atlantic population of white sharks, their primary regional predator, were apparent in visual and acoustic surveys designed to detect coastal visitation of sharks. Fig. 5 emphasizes the seasonal pulse of predation pressure through cumulative distribution functions of shark detections around Cape Cod. We detected 24 individually tagged sharks at 16 acoustic receiver sites in Cape Cod during the 2 years (Table 3 ). Of tags active in both sampling years ( $\mathrm{n}=13$ individuals), $85 \%$ ( $\mathrm{n}=11$ individuals) were detected each year (Table 3). In 2014, 11 additional individuals were tagged and detected (Table 3).

Seasonal patterns of detection were consistent between methods and across years (Tables S4 \& S5 in Section 3 in the Supplement), with coastal presence of sharks beginning around June and increasing rapidly through summer months. On average annually, a tagged shark was observed at $>50 \%$ of receiver stations (mean $=50.91 \%$; Table 3 ) and detected on over 20 unique days (mean $=21.76$ total days detected; Table 3). Average duration until subsequent detection of that individual on another day was just over 1 wk (mean $=8.876 \mathrm{~d}$ i Table 3 ). While individual presence varied, predation risk imposed by coastal shark visitation was present throughout the season and across days (Table 3; Tables S4 \& S5). Cumulative distribution functions of both visual and acoustic data surpassed 0.5 in August (Fig. 5), when seals exhibited their most constrained home ranges (Table 1 , Fig. 1). Detections reached their annual maximum just following the seasonal breakpoint in seal spatial behavior during November (Figs. $1 \& 5$ ).

\subsection{Shark-seal interactions}

White shark activity cycles exhibited clear seasonal (Fig. 5) and diel patterns (Fig. 6). We observed a diel cycle of inshore visitation in tagged sharks detected at the listening array (Fig. 2a), with activity peaks around local sunrise, sunset, and midnight (Fig. 6). Overlaying coastal pulses of white sharks (Fig. 5) with nocturnal foraging of tagged gray seals (Figs. $3 \& 6$ ), 

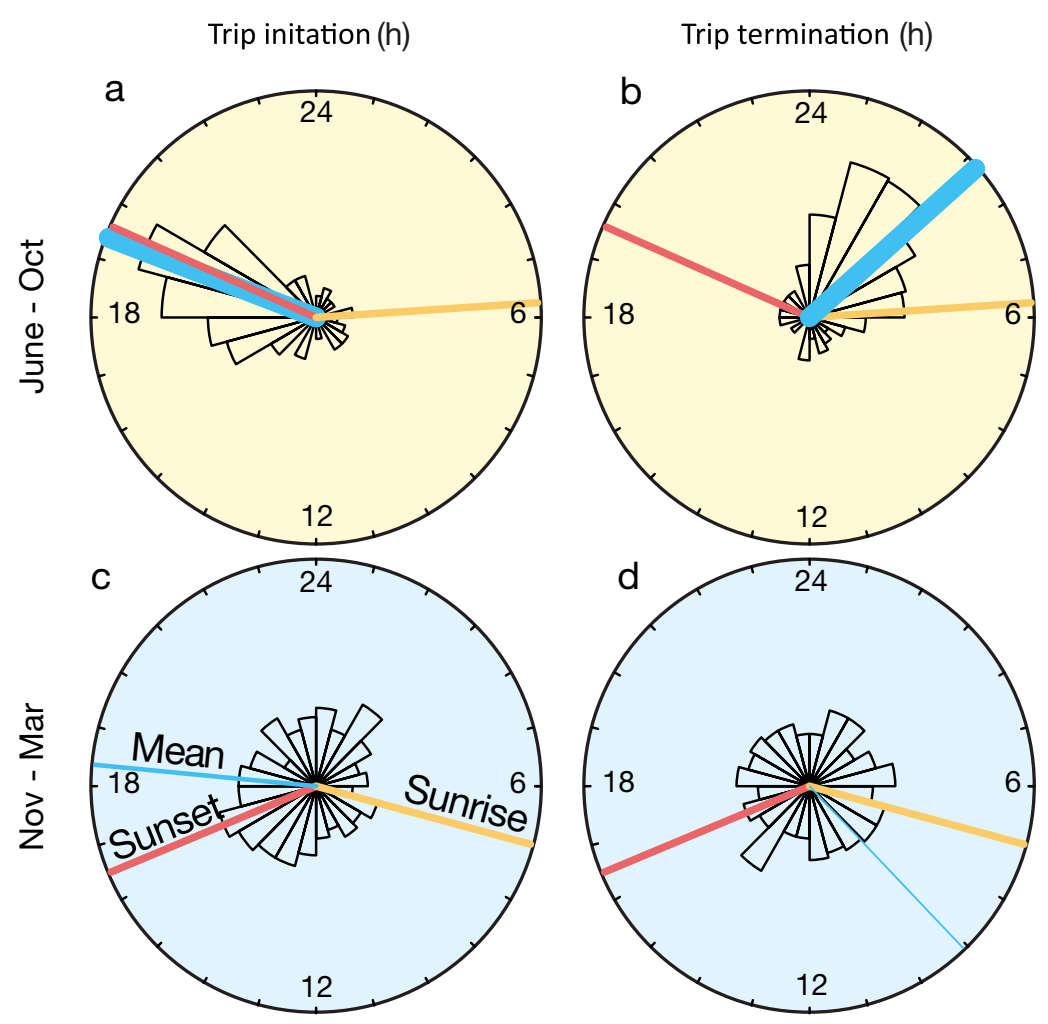

Fig. 3. Circular distributions of $(\mathrm{a}, \mathrm{c})$ the start (i.e. trip initiation) and $(\mathrm{b}, \mathrm{d})$ the end (i.e. trip termination) in seasonal foraging trips depict diel timing of at-sea behavior for tagged gray seals. Foraging trips in $(a, b)$ June through October show a clear nocturnal pattern consistent across all tagged individuals, with seasonal averages of the timing of sunset and sunrise depicted in red and orange bars, respectively. Blue bars depict the mean resultant vector of the distribution, with thickness scaled to the strength of the central tendency. (c,d) Between November and March, this coherent pattern dissipates as individual foraging behavior and spatial ecology became highly variable

diel variation in risk encountered by seals aligned with their observed movement patterns. The mean departure vector of foraging seals (mean $\bar{\theta} \pm 95 \% \mathrm{CI}=$ $-1.21 \pm 0.06$ radians; i.e. 19:00-19:30 h local time; Fig. 3a) was directly coincident with diurnal maxima in coastal activity of sharks, indicative of high predation risk when beginning nocturnal foraging (blue 'seals depart' arrow; Fig. 6). However, following a night of foraging, trip terminations (mean $\bar{\theta} \pm$ $95 \% \mathrm{CI}=0.84 \pm 0.77$ radians; i.e. 03:00-03:30 h; Fig. 3b) aligned directly with nocturnal minima in shark activity (blue 'seals return' arrow; Fig. 6). In contrast, the fatally wounded seal's final traverse occurred 75 min after sunrise (06:55 h, 2 August 2013; Fig. 4b), when morning shark activity would be near maximum (Fig. 6). Two tagged sharks $(32314,32307)$ were detected at nearby receivers within $2 \mathrm{~h}$ of this seal's coastal traverse.

\section{DISCUSSION}

Given rising shark-seal interactions on Cape Cod (Skomal et al. 2012), gray seals must target their prey while avoiding predators for safe and effective foraging. Such food-safety tradeoffs are ubiquitous in nature, but are not well explored for many marine predators like gray seals (Wirsing et al. 2008, Kiszka et al. 2015). Our results demonstrate that individual seals responded similarly to risk of predation, restricting temporal and spatial use within small, overlapping areas when predator activity was strongest. Trips to sea were predominantly nocturnal and exhibited homogeneous selection of dark periods around twilight when traversing risky areas nearby haul outs. Such a high degree of uniform nearshore movement has not been observed in other well-studied gray seal colonies (McConnell et al. 1999, Austin et al. 2006, Breed et al. 2013, Russell et al. 2015), where more tagging work has been conducted but there may be a lesser influence of predation risk. Additional tagging of gray seals in Cape Cod can evaluate the prevalence of these patterns at a population scale (Sequeira et al. 2019). In combination, this dominant behavioral uniformity suggested that individual seals on Cape Cod perceive the magnitude of risk similarly, and individually variable responses were not likely advantageous.

Variability in individual seal behavior emerged strongly as predation risk declined (Figs. 1 \& 2) and movement patterns became more comparable to typical movements observed at other colonies (Fig. 3). Cohesive use of nocturnal periods dissipated, as seals initiated and terminated trips throughout the day with no reference to crepuscular periods (Figs. $3 \& 4$ ). If the rapid emergence of individually variable behavior remains consistent at more population scales, it may represent attempts to reduce intraspecific competition and optimize diet/intake prior to breeding in December/January. As capital breeders, gray seals fast during the breeding season and endure significant reductions in body condition (Beck et al. 2000). Seasonal shifts in prey distribution are also expected to affect movements, but not in such a uniform manner. Tagged individuals' transition from cohesive movements with homogeneous diel selection 


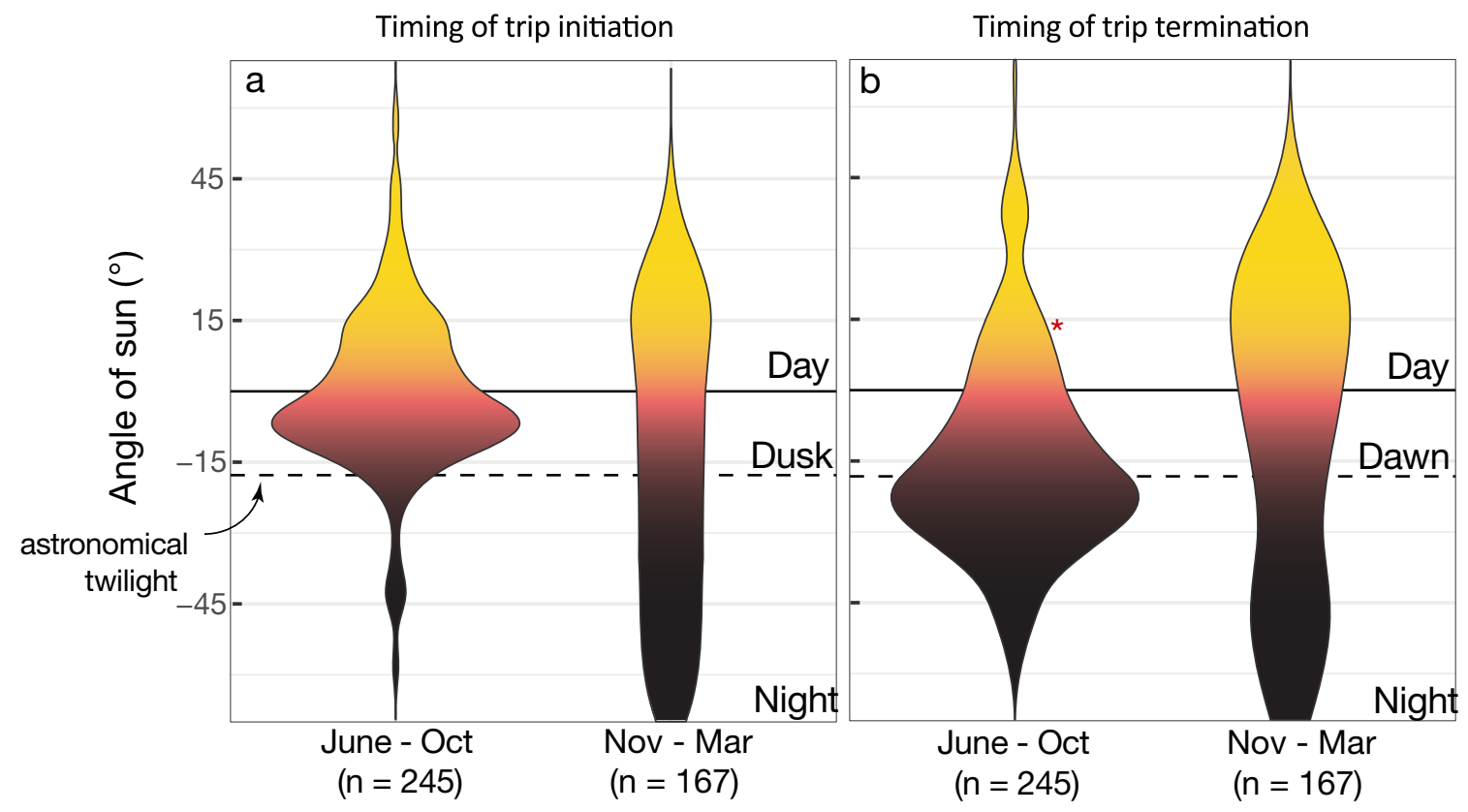

Fig. 4. Seasonal comparisons in the crepuscular preference of (a) trip initiations and (b) trip terminations exhibit strong temporal patterns in warm months only (June to October). Violin plots show data density in relation to the solar elevation angle, which estimates the angle of the sun in relation to the horizon. Thus, moments of sunrise and sunset are defined by an angle = $0^{\circ}$ when the sun crosses the horizon's plane. In warm months, seals initiated trips during twilight at and around sunset (a). Upon return, however, seals used darkness prior to twilight in greater proportions (b). The dashed line at $-18^{\circ}$ in relation to the horizon denotes 'astronomical twilight', marking the first or last moments of light in a completely dark sky. The asterisk ( $\left.{ }^{*}\right)$ in

(b) marks the termination of a wounded seal's final trip to sea

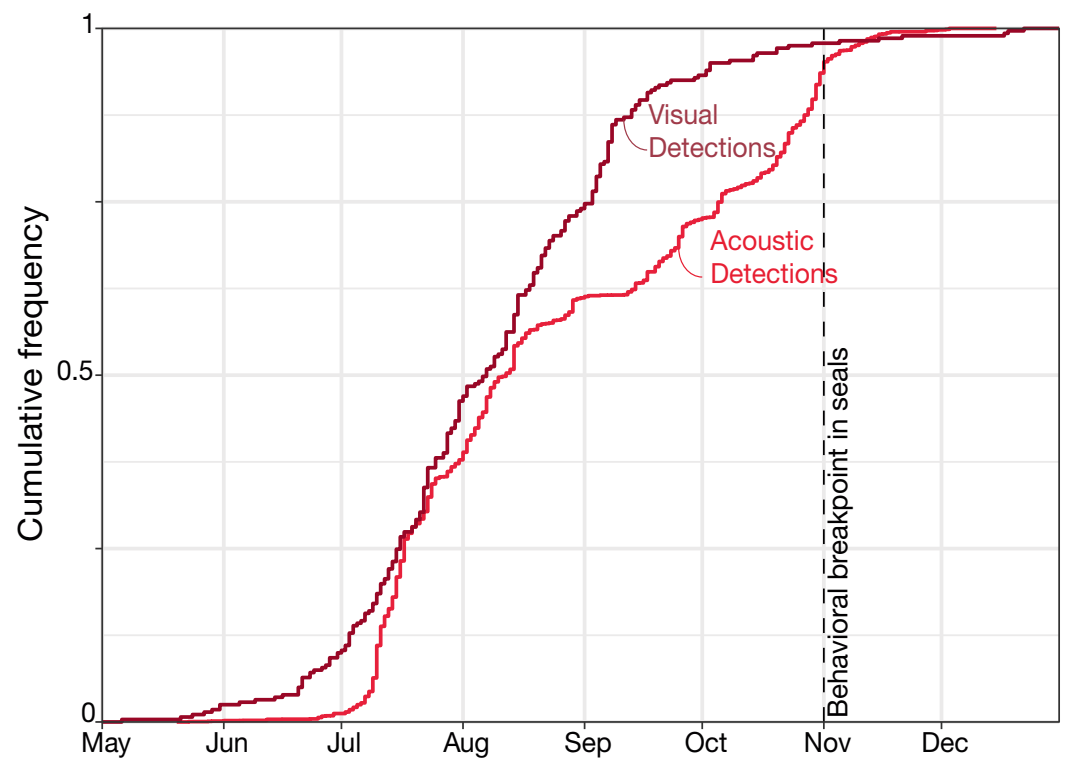

Fig. 5. Seasonal pulse of predation pressure around Cape Cod is apparent in cumulative distribution functions of white shark detections, either from visual surveys (dark red) or acoustic detections (light red). Sharks are detected throughout warm summer and fall months in proximity to seal haul outs before they disperse after water temperatures cool (Skomal et al. 2017). The behavioral breakpoint in seal behavior (see Fig. 1) is plotted for reference to broader-ranging movements with individual variability suggested a greater potential for top-down behavioral modulation in seal behavior.

Animals can exploit temporal variation in predation risk cycles to enhance their survival and foraging success (Lima \& Bednekoff 1999). In the present study, seals appeared to reduce daytime at sea to reduce predation risk, hauling out frequently (Moxley et al. 2017) and focusing at-sea behavior nocturnally (Fig. 3). On the whole, tagged individuals targeted reduced light conditions, but diel selection depended on the direction of travel (Fig. 5). Dusk and dawn peaks in shark detections indicated predatory targeting behavior, particularly at dusk when dynamics in nearshore activity of sharks and seals aligned (Fig. 6). Seals returning before dawn, however, avoided increasing shark detections after daybreak (Fig. 6), resulting in a predator-prey mismatch.

Inherent differences in trip segments might affect the seals' perception and tolerance of risk. As gray seals begin forag- 
Table 3. Summary of detections for individually tagged white sharks during the 2013 and 2014 sampling years. Most individuals were detected at a majority of sites across numerous days. Days between subsequent detections indicate that tagged sharks continually visit the same sites throughout the season, imposing continued predation pressure alongside any other sharks within the area. (-) Unknown/ no data

\begin{tabular}{|c|c|c|c|c|c|c|c|c|c|c|}
\hline \multirow{2}{*}{$\begin{array}{l}\text { Shark } \\
\text { ID }\end{array}$} & \multirow{2}{*}{$\begin{array}{l}\text { Years } \\
\text { tagged }\end{array}$} & \multirow[t]{2}{*}{ Sex } & \multirow{2}{*}{$\begin{array}{c}\text { Total } \\
\text { length }(\mathrm{m})\end{array}$} & \multirow{2}{*}{$\begin{array}{c}\text { Sampling } \\
\text { year }\end{array}$} & \multicolumn{3}{|c|}{ Sites detected } & \multicolumn{3}{|c|}{ —Days between detections } \\
\hline & & & & & No. & $\%$ & Total days & Median & $\mathrm{SD}$ & Max \\
\hline \multirow[t]{2}{*}{ WS11-03 } & 4 & - & 2.7 & 2013 & 2 & 13.33 & 4 & 3.989 & 2.114 & 5.65 \\
\hline & & & & 2014 & 10 & 66.67 & 6 & 2.211 & 64.109 & 130.56 \\
\hline \multirow[t]{2}{*}{ WS11-05 } & 4 & M & 4.3 & 2013 & 13 & 86.67 & 44 & 12.031 & 13.332 & 93.71 \\
\hline & & & & 2014 & 6 & 40.00 & 6 & 19.899 & 19.232 & 54.85 \\
\hline \multirow[t]{2}{*}{ WS12-01 } & 3 & M & 3.7 & 2013 & 11 & 73.33 & 91 & 28.106 & 33.971 & 122.86 \\
\hline & & & & 2014 & 9 & 60.00 & 57 & 16.285 & 14.604 & 65.24 \\
\hline \multirow[t]{2}{*}{ WS12-08 } & 3 & $\mathrm{M}$ & 3.7 & 2013 & - & - & - & 0 & - & - \\
\hline & & & & 2014 & 11 & 73.33 & 38 & 7.879 & 17.443 & 158.54 \\
\hline \multirow[t]{2}{*}{ WS12-09 } & 3 & - & 4.2 & 2013 & - & - & - & 0 & - & - \\
\hline & & & & 2014 & 4 & 26.67 & 8 & 11.526 & 18.13 & 71.22 \\
\hline \multirow[t]{2}{*}{ WS12-10 } & 3 & - & 3.4 & 2013 & 2 & 13.33 & 1 & 0.005 & 0.2 & 0.51 \\
\hline & & & & 2014 & 3 & 20.00 & 1 & 0.017 & 0.161 & 0.38 \\
\hline \multirow[t]{2}{*}{ WS12-14 } & 3 & - & 4.3 & 2013 & 8 & 53.33 & 41 & 18.313 & 16.191 & 83.27 \\
\hline & & & & 2014 & - & - & - & - & - & - \\
\hline \multirow[t]{2}{*}{ WS12-15 } & 3 & - & 4.3 & 2013 & 5 & 33.33 & 30 & 7.069 & 7.174 & 46.08 \\
\hline & & & & 2014 & 11 & 73.33 & 8 & 3.473 & 2.69 & 9.54 \\
\hline \multirow[t]{2}{*}{ WS12-16 } & 3 & $\mathrm{~F}$ & 4.5 & 2013 & 6 & 40.00 & 18 & 21.316 & 18.453 & 76.52 \\
\hline & & & & 2014 & 7 & 46.67 & 15 & 12.297 & 10.009 & 42.4 \\
\hline \multirow[t]{2}{*}{ WS13-02 } & 2 & $\mathrm{~F}$ & 3.8 & 2013 & 4 & 26.67 & 10 & 2.954 & 5.09 & 20.72 \\
\hline & & & & 2014 & 11 & 73.33 & 17 & 16.465 & 13.709 & 46.65 \\
\hline \multirow[t]{2}{*}{ WS13-03 } & 2 & $\mathrm{~F}$ & 4.3 & 2013 & 5 & 33.33 & 41 & 15.878 & 20.216 & 96.65 \\
\hline & & & & 2014 & 9 & 60.00 & 32 & 6.248 & 11.546 & 75.49 \\
\hline \multirow[t]{2}{*}{ WS13-04 } & 2 & $\mathrm{~F}$ & 4 & 2013 & 8 & 53.33 & 20 & 19.217 & 17.753 & 65.5 \\
\hline & & & & 2014 & 10 & 66.67 & 7 & 1.699 & 2.26 & 9.74 \\
\hline \multirow[t]{2}{*}{ WS13-05 } & 2 & $\mathrm{~F}$ & 4.9 & 2013 & 6 & 40.00 & 20 & 10.042 & 7.592 & 46.62 \\
\hline & & & & 2014 & - & - & - & 0 & - & - \\
\hline WS14-08 & 1 & M & 4.2 & 2014 & 11 & 73.33 & 50 & 23.493 & 19.15 & 74.46 \\
\hline WS14-17 & 1 & M & 4 & 2014 & 12 & 80.00 & 49 & 19.956 & 15.593 & 69.7 \\
\hline WS14-18 & 1 & M & 3.8 & 2014 & 11 & 73.33 & 25 & 6.967 & 7.889 & 41.43 \\
\hline WS14-23 & 1 & $\mathrm{M}$ & 4 & 2014 & 11 & 73.33 & 36 & 15.961 & 15.433 & 65.02 \\
\hline WS14-27 & 1 & $\mathrm{M}$ & - & 2014 & 9 & 60.00 & 6 & 1.073 & 2.383 & 8.21 \\
\hline WS14-44 & 1 & $\mathrm{M}$ & 3.7 & 2014 & 6 & 40.00 & 4 & 1.085 & 0.848 & 3.08 \\
\hline WS14-49 & 1 & $\mathrm{~F}$ & 4.6 & 2014 & 9 & 60.00 & 9 & 3.212 & 2.757 & 8.6 \\
\hline WS14-50 & 1 & $\mathrm{~F}$ & 4.2 & 2014 & 9 & 60.00 & 18 & 9.98 & 8.17 & 32.34 \\
\hline WS14-57 & 1 & $\mathrm{~F}$ & 4.2 & 2014 & 6 & 40.00 & 2 & 0.271 & 0.25 & 0.92 \\
\hline WS14-61 & 1 & $\mathrm{~F}$ & - & 2014 & 4 & 26.67 & 3 & 0.54 & 0.587 & 1.64 \\
\hline WS14-68 & 1 & $\mathrm{~F}$ & 3.5 & 2014 & 3 & 20.00 & 1 & 0.079 & 0.041 & 0.11 \\
\hline
\end{tabular}

ing trips from shared haul outs, synchronized departures like those observed here (Fig. 4a) likely diluted risk, as seen in large penguin rafts entering the water en masse (Krause et al. 2002, Daniel et al. 2007). However, after a night of solitary foraging, less synchronous timing of trip terminations (Fig. 4b) would arise through individual variability in endurance, foraging success, and/or satiation. For pinnipeds subject to white shark predation elsewhere, groups of departing seals were 4-5 times larger than animals returning typically in pairs or as individuals (de Vos et al. 2015). Without effective group formation at sea, returning seals may counter predatory tactics differ- ently and respond more strongly to the emerging illumination (Fig. 5, Fallows et al. 2016).

Additional differences between outbound and inbound trip segments could influence the effectiveness of anti-predator strategies. Associated changes in an animal's motivational state (e.g. feeding vs. digesting) and energy level (e.g. rested vs. tired) in the course of a foraging trip may impact the efficacy of defensive and/or vigilant behavior. Similarly, returning to individual colony sites likely incurs greater navigational burden than outbound legs targeting multiple at-sea foraging patches. The effect of navigational complexity may be more influential on Cape 


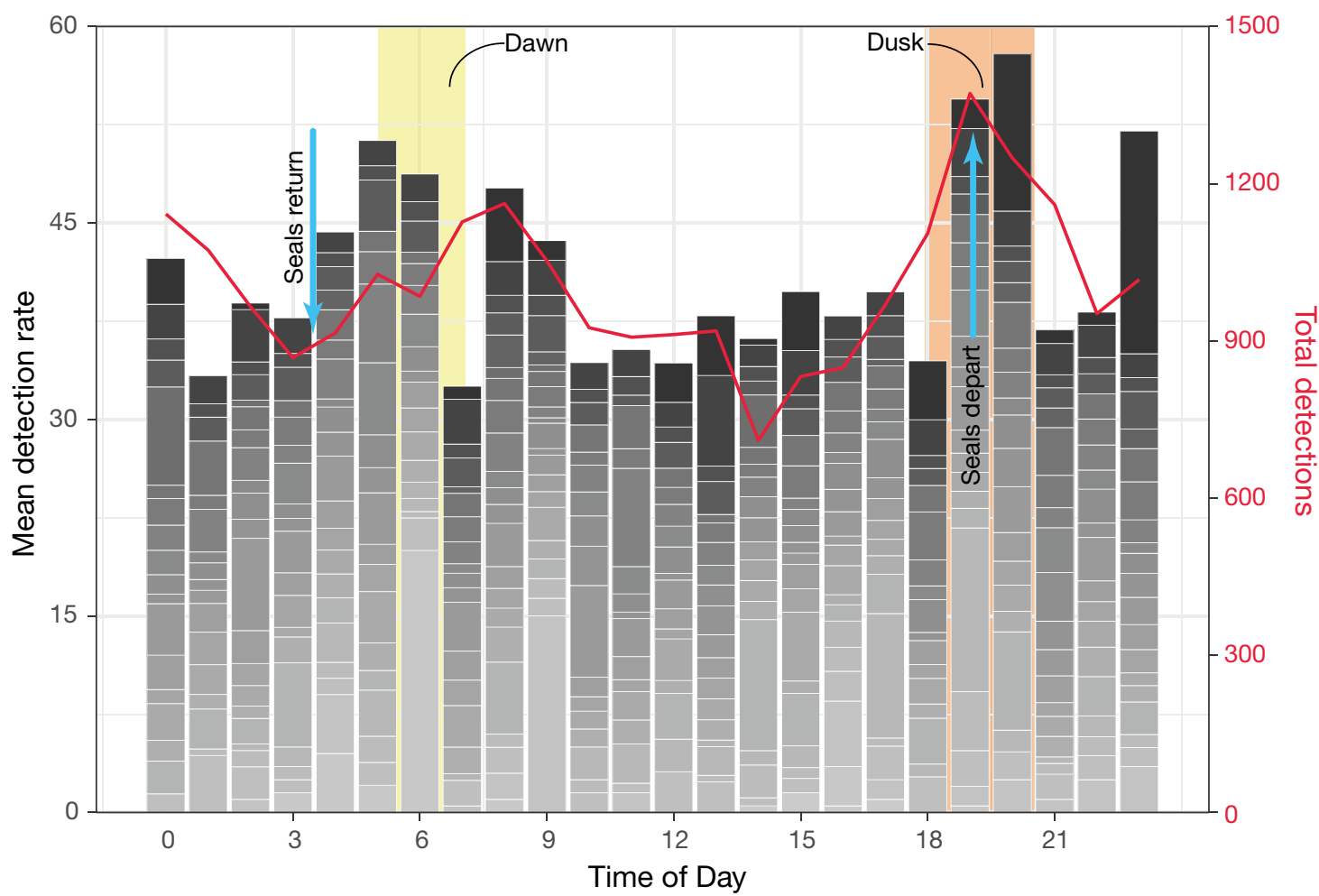

Fig. 6. Diel cycles in white shark detections at nearshore monitoring stations reveal temporal match/mismatch in predator and prey activity. Peak detections of white sharks aligned with the mean departure vector of seals departing the beach at dusk, but were offset when seals returned prior to dawn. White shark activity is shown as average daily rates (gray bars with different shading representing individuals) and total detections (red line) by hour. Average periods of dawn and dusk are shown in yellow and orange, respectively

Cod, where seals often must maneuver movement bottlenecks like coastal inlets, tidal sandbars, and restricted entry/exit points near haul outs. Visually, trip segments differ in terms of eyesight alignment (e.g. towards deeper vs. shallower depths) or direction of sun glare (e.g. from west vs. from east).

Gray seals undergo breeding and molting fasts annually, and associated changes in body condition can affect movement patterns and foraging habits, and may influence food-safety tradeoffs (Beck et al. 2000, Breed et al. 2009). Some degree of seasonal movement difference will reflect heightened energetic demands during winter months. However, the homogeneous behavior during warm months indicated common strategies among individuals for foraging and survival prior to wintertime reproduction. Sand lance (Ammodytes spp.) are a particularly common diet item (Beck et al. 2007, Ampela 2009), and predominated the stomach contents of gray seals caught within fishing gear near the study area (Wenzel et al. 2017). Knowledge gaps and limitations regarding sand lance, which are not sampled well by trawl methods and exhibit extreme patchiness, precluded resolving distributional patterns at a fine- enough scale to match this study (Staudinger et al. 2020).

Described as generalist in the literature, the gray seal diet is typically quite diverse (Beck et al. 2007, Ampela 2009), and movements are often emphasized for individual, demographic, and sexual variability (Austin et al. 2006, Breed et al. 2009, Russell et al. 2015). Compared to elsewhere, gray seal movement around Cape Cod during warmer months concentrated more heavily nearshore. Most (98\%) movements during the riskier warm season occurred within $10 \mathrm{~km}$ of the coastline, compared to $40-80 \%$ observed at other colonies (McConnell et al. 1999, Breed et al. 2013). Contrary to expectations of greater behavioral and spatial variability, the seasonal uniformity of behavior suggested greater influence of indiscriminate forces like top-down predation. A generalist species that exhibits degrees of individual preference might respond more variably to bottom-up changes such as prey distribution shifts. If individually variable responses to predation risk are not advantageous, these seals may manage food-safety tradeoffs by focusing on survival during risky seasons and shifting quickly to compensatory foraging later. 
Understanding the ecological interactions arising from conservation successes - such as gray seals and white sharks in the Northwest Atlantic - is essential for comprehensive management of marine natural resources (Cammen et al. 2019). The re-emergence of predatory interactions and avoidance behaviors of gray seals off Cape Cod was in stark contrast with observations from colonies subjected to less predation, where such anti-predator behavior has not been specifically reported. Expectedly, robust predatory shark populations will affect consumption patterns of seals, and likely influence subsequent fishery impacts. On the other hand, the return of white sharks to a coastal region that relies on beach tourism creates challenges for predator conservation (Ferretti et al. 2015). Given the rapid growth of gray seals on Cape Cod (Moxley et al. 2017, Wood et al. 2020), additional tagging is essential for broadening these findings at a population and regional scale. Additionally, physiological approaches that document stress response and glucocorticoid levels provide promise for quantifying risk landscapes and behavioral response at cost-effective scales (Hammerschlag et al. 2017).

Growing predator populations can complicate single-species conservation aims, and impact ecosystem restoration more broadly (Marshall et al. 2016, Cammen et al. 2019, Moxley et al. 2019), especially where predation risk structures food-web interactions (Schmitz et al. 1997, Laundré et al. 2014). Our study complements others like it (Breed et al. 2017, Jorgensen et al. 2019, Moxley et al. 2019) that demonstrate the importance of multi-species approaches to understanding animal behavior and habitat use (Block et al. 2011, Brodie et al. 2018). Our results provide an intriguing model for evaluating predation effects in coastal marine predators elsewhere (e.g. killer whales and pinnipeds in the Shetland Islands; Deecke et al. 2011). These unexpected (and sometimes surprising) ecological interactions that emerge from conservation gains can have large impacts on the dynamics of ecosystem restoration (Doak et al. 2008, Silliman et al. 2018, Moxley et al. 2019).

Acknowledgements. All gray seal tagging activities on Cape Cod were conducted under appropriate permits (NMFS Scientific Research Permit 17670, Cape Cod National Park Service Special Use Permit CACO-2013-SCI-0015, and MMPA/ESA Research and Enhancement Permit 9321905/MA-009526), led by the Northeast Fisheries Science Center, and funded by the Bureau of Ocean Energy Management. The seal tagging project was approved by the NMFS Atlantic IACUC Committee IACUC-2011-005. Support from the International Fund for Animal Welfare and the Oak Foundation provided telemetry tags deployed on seals. Field work on gray seals was accomplished by a collabora- tive multi-party group, including partners from Woods Hole Oceanographic Institution, Provincetown Center for Coastal Studies, International Fund for Animal Welfare, Riverhead Center for Marine Research and Preservation, Division of Fisheries and Oceans Canada, NMFS Protected Species Branch, and the Northwest Atlantic Seal Research Consortium. All shark tagging activities were conducted under NMFS Exempted Fishing Permits (SHK-EFP-11-04, SHKEFP-12-08, SHK-EFP-13-01) issued to the Massachusetts Division of Marine Fisheries and funded by Federal Aid in Sport Fish Restoration, the John J. Sacco and Edith L. Sacco Charitable Foundation, and the Atlantic White Shark Conservancy. Figure design, including development of the tequila sunrise palette, could not have been possible without Monterey Bay Aquarium's Conservation Research team. This manuscript was greatly improved with helpful reviews from anonymous reviewers and collaboration with colleagues D. Dunn, C. Curtice, A. Boustany, J. Gilbert, J. Clark, S. Jorgensen, and K. Van Houtan.

\section{LITERATURE CITED}

Ampela K (2009) The diet and foraging ecology of gray seals (Halichoerus grypus) in United States waters. PhD dissertation, The City University of New York, New York, NY

Austin D, Bowen W, McMillan J, Iverson S (2006) Linking movement, diving, and habitat to foraging success in a large marine predator. Ecology 87:3095-3108

Beck CA, Bowen WD, Iverson SJ (2000) Seasonal changes in buoyancy and diving behaviour of adult grey seals. J Exp Biol 203:2323-2330

Beck CA, Iverson SJ, Bowen WD, Blanchard W (2007) Sex differences in grey seal diet reflect seasonal variation in foraging behaviour and reproductive expenditure: evidence from quantitative fatty acid signature analysis. J Anim Ecol 76:490-502

* Bednekoff PA, Lima SL (2011) Risk allocation is a general phenomenon: a reply to Beauchamp and Ruxton. Am Nat 177:147-151

* Bernt KE, Hammill MO, Kovacs KM (1996) Age estimation of grey seals (Halichoerus grypus) using incisors. Mar Mamm Sci 12:476-482

Block BA, Jonsen ID, Jorgensen SJ, Winship AJ and others (2011) Tracking apex marine predator movements in a dynamic ocean. Nature 475:86-90

Breed GA, Jonsen ID, Myers RA, Bowen WD, Leonard ML (2009) Sex-specific, seasonal foraging tactics of adult grey seals (Halichoerus grypus) revealed by state-space analysis. Ecology 90:3209-3221

*Beed GA, Bowen WD, Leonard ML (2013) Behavioral signature of intraspecific competition and density dependence in colony breeding marine predators. Ecol Evol 3: 3838-3854

Breed GA, Matthews CJ, Marcoux M, Higdon JW and others (2017) Sustained disruption of narwhal habitat use and behavior in the presence of Arctic killer whales. Proc Natl Acad Sci USA 114:2628-2633

* Brodie S, Lédée EJI, Heupel MR, Babcock RC and others (2018) Continental-scale animal tracking reveals functional movement classes across marine taxa. Sci Rep 8:3717

* Brown JS, Kotler BP (2004) Hazardous duty pay and the foraging cost of predation. Ecol Lett 7:999-1014

* Brown AC, Lee DE, Bradley RW, Anderson S (2010) Dynamics of white shark predation on pinnipeds in California: effects of prey abundance. Copeia 2010:232-238 
Calenge C (2006) The package "adehabitat" for the R software: tool for the analysis of space and habitat use by animals. Ecol Model 197:516-519

* Cammen KM, Rasher DB, Steneck RS (2019) Predator recovery, shifting baselines, and the adaptive management challenges they create. Ecosphere 10:e02579

Caro T (2005) Antipredator defenses in birds and mammals. University of Chicago Press, Chicago, IL

* Chow GC (1960) Tests of equality between sets of coefficients in two linear regressions. Econometrica 28: 591-605

* Creel S (2011) Toward a predictive theory of risk effects: hypotheses for prey attributes and compensatory mortality. Ecology 92:2190-2195

Creel S, Winnie J, Christianson D, Liley S (2008) Time and space in general models of antipredator response: tests with wolves and elk. Anim Behav 76:1139-1146

* Curtis TH, McCandless CT, Carlson JK, Skomal GB (2014) Seasonal distribution and historic trends in abundance of white sharks, Carcharodon carcharias, in the Western North Atlantic Ocean. PLOS ONE 9:e99240

* Daniel TA, Chiaradia A, Logan M, Quinn GP, Reina RD (2007) Synchronized group association in little penguins, Eudyptula minor. Anim Behav 74:1241-1248

de Vos A, O'Riain MJ (2013) Movement in a selfish seal herd: Do seals follow simple or complex movement rules? Behav Ecol 24:190-197

de Vos A, O'Riain MJ, Meÿer MA, Kotze PGH, Kock AA (2015) Behavior of Cape fur seals (Arctocephalus pusillus pusillus) in response to spatial variation in white shark (Carcharodon carcharias) predation risk. Mar Mamm Sci 31:1234-1251

Deecke VB, Nykänen M, Foote AD, Janik VM (2011) Vocal behaviour and feeding ecology of killer whales Orcinus orca around Shetland, UK. Aquat Biol 13:79-88

Doak DF, Estes JA, Halpern BS, Jacob U and others (2008) Understanding and predicting ecological dynamics: Are major surprises inevitable? Ecology 89:952-961

Fallows C, Martin R, Hammerschlag N (2012) Comparisons between white shark-pinniped interactions at Seal Island (South Africa) with other sites in California. In: Domeier ML (ed) Global perspectives on the biology and life history of the white shark. CRC Press, Boca Raton, FL, p 105-117

Fallows C, Fallows M, Hammerschlag N (2016) Effects of lunar phase on predator-prey interactions between white shark (Carcharodon carcharias) and Cape fur seals (Arctocephalus pusillus pusillus). Environ Biol Fishes 99: 805-812

F Ferrari M, Chivers DP (2009) Temporal variability, threat sensitivity and conflicting information about the nature of risk: understanding the dynamics of tadpole antipredator behaviour. Anim Behav 78:11-16

Ferretti F, Jorgensen S, Chapple T, De Leo G, Micheli F (2015) Reconciling predator conservation with public safety. Front Ecol Environ 13:412-417

Hammerschlag N, Meÿer M, Seakamela SM, Kirkman S, Fallows C, Creel S (2017) Physiological stress responses to natural variation in predation risk: evidence from white sharks and seals. Ecology 98:3199-3210

Hammill M, Stenson G (2014) Feeding by grey seals on endangered stocks of Atlantic cod and white hake. ICES J Mar Sci 71:1332-1341

Hammill MO, den Heyer CE, Bowen WD, Lang SLC (2017) Grey seal population trends in Canadian waters, 1960-
2016 and harvest advice. Res Doc 2017/052. DFO, Canadian Science Advisory Secretariat, Ottawa, ON

*Henning C (2020) Fpc: flexible procedures for clustering. $\mathrm{R}$ package version 2.2-5. https://cran.r-project.org/web/ packages/fpc/fpc.pdf

Jewell OJD, Gleiss AC, Jorgensen SJ, Andrzejaczek S and others (2019) Cryptic habitat use of white sharks in kelp forest revealed by animal-borne video. Biol Lett 15: 20190085

* Johnson DS, London JM, Lea MA, Durban JW (2008) Continuous-time correlated random walk model for animal telemetry data. Ecology 89:1208-1215

Jorgensen SJ, Anderson S, Ferretti F, Tietz JR and others (2019) Killer whales redistribute white shark foraging pressure on seals. Sci Rep 9:6153

Keating KA, Cherry S (2009) Modeling utilization distributions in space and time. Ecology 90:1971-1980

KKiszka JJ, Heithaus MR, Wirsing AJ (2015) Behavioural drivers of the ecological roles and importance of marine mammals. Mar Ecol Prog Ser 523:267-281

Klimley AP, Pyle P, Anderson SD (1996) The behavior of white sharks and their pinniped prey during predatory attacks. In: Klimley AP, Ainley DG (eds) Great white sharks: the biology of Carcharodon carcharias. Academic Press, San Diego, CA, p 175-191

Klimley AP, Le Boeuf B, Cantara K, Richert J, Van Sommeran S, Davis S, Kelly JT (2001) The hunting strategy of white sharks (Carcharodon carcharias) near a seal colony. Mar Biol 138:617-636

Krause J, Ruxton GD, Ruxton IG (2002) Living in groups. Oxford University Press, New York, NY

* Laroche R, Kock A, Dill L, Oosthuizen W (2008) Running the gauntlet: a predator-prey game between sharks and two age classes of seals. Anim Behav 76:1901-1917

*Laundré JW, Hernández L, Medina PL, Campanella A and others (2014) The landscape of fear: the missing link to understand top-down and bottom-up controls of prey abundance? Ecology 95:1141-1152

Le Boeuf BJ, Crocker DE (1996) Diving behavior of elephant seals: implications for predator avoidance. In: Klimley AP, Ainley DG (eds) Great white sharks: the biology of Carcharodon carcharias. Academic Press, San Diego, CA, p 193-205

Lelli B, Harris DE, Aboueissa AM (2009) Seal bounties in Maine and Massachusetts, 1888 to 1962. Northeast Nat 16:239-254

* Lewin-Koh NJ, Bivand R (2011) maptools: tools for reading and handling spatial objects. $\mathrm{R}$ package version $0.8-23$. https://cran.r-project.org/web/packages/maptools/index .html

Lima SL, Bednekoff PA (1999) Temporal variation in danger drives antipredator behavior: the predation risk allocation hypothesis. Am Nat 153:649-659

* Lima SL, Dill LM (1990) Behavioral decisions made under the risk of predation: a review and prospectus. Can J Zool 68:619-640

Lund U, Agostinelli C (2017) Package 'circular'. R package version 0.4-7. https://r-forge.r-project.org/projects/circular/

* Marshall KN, Stier AC, Samhouri JF, Kelly RP, Ward EJ (2016) Conservation challenges of predator recovery. Conserv Lett 9:70-78

Martin R, Hammerschlag N, Collier RS, Fallows C (2005) Predatory behaviour of white sharks (Carcharodon carcharias) at Seal Island, South Africa. J Mar Biol Assoc UK 85:1121-1135 
McConnell BJ, Fedak MA, Lovell P, Hammond PS (1999) Movements and foraging areas of grey seals in the North Sea. J Appl Ecol 36:573-590

Moxley JH, Bogomolni A, Hammill MO, Moore KMT and others (2017) Google Haul Out: earth observation imagery and digital aerial surveys in coastal wildlife management and abundance estimation. Bioscience 67:760-768

Moxley JH, Nicholson TE, Van Houtan KS, Jorgensen SJ (2019) Non-trophic impacts from white sharks complicate population recovery for sea otters. Ecol Evol 9:6378-6388

O'Boyle R, Sinclair M (2012) Seal-cod interactions on the Eastern Scotian Shelf: reconsideration of modelling assumptions. Fish Res 115-116:1-13

Olsson O, Brown JS, Helf KL (2008) A guide to central place effects in foraging. Theor Popul Biol 74:22-33

Orians GH, Pearson NE (1979) On the theory of central place foraging. In: Horn DJ, Stairs GR, Mitchell DR (eds) Analysis of ecological systems. Ohio State University Press. Columbus, OH, p 157-177

Pewsey A, Neuhäuser M, Ruxton GD (2013) Circular statistics in R. Oxford University Press, Oxford

Pincock DG (2012) False detections: what they are and how to remove them from detection data. VEMCO Whitepaper Document DOC-004691, v03. Amirix Systems Inc, Halifax

Pinheiro J, Bates D, DebRoy S, Sarkar D, Heisterkamp S, Van Willigen B (2017) Package 'nlme': linear and nonlinear mixed effects models, version 3. https://cran.rproject.org/web/packages/nlme/index.html

Reynolds JE III, Odell DK, Rommel SA (1999) Marine mammals of the world. In: Reynolds JE, Rommel SA (eds) Biology of marine mammals. Smithsonian Institution Press, Washington, DC

Russell DJF, McClintock BT, Matthiopoulos J, Thompson PM and others (2015) Intrinsic and extrinsic drivers of activity budgets in sympatric grey and harbour seals. Oikos 124:1462-1472

Schmitz OJ, Beckerman AP, O'Brien KM (1997) Behaviorally mediated trophic cascades: effects of predation risk on food web interactions. Ecology 78:1388-1399

Sequeira AMM, Heupel MR, Lea MA, Eguiluz VM and others (2019) The importance of sample size in marine megafauna tagging studies. Ecol Appl 29:e01947

Editorial responsibility: Peter Corkeron, Woods Hole, Massachusetts, USA
Silliman BR, Hughes BB, Gaskins LC, He Q and others (2018) Are the ghosts of nature's past haunting ecology today? Curr Biol 28:R532-R537

Skomal G, Chisholm J, Correia S (2012) Implications of increasing pinniped populations on the diet and abundance of white sharks off the coast of Massachusetts. In: Domeier ML (ed) Global perspectives on the biology and life history of the white shark. CRC Press, Boca Raton, FL, p 405-418

Skomal GB, Braun CD, Chisholm JH, Thorrold SR (2017) Movements of the white shark Carcharodon carcharias in the North Atlantic Ocean. Mar Ecol Prog Ser 580: $1-16$

Staudinger M, Goyert H, Suca JJ, Coleman K and others (2020) The role of sand lances (Ammodytes sp.) in the Northwest Atlantic Ecosystem: a synthesis of current knowledge with implications for conservation and management. Fish Fish 21:522-556

Tricas TC, McCosker JE (1984) Predatory behavior of the white shark (Carcharodon carcharias), with notes on its biology. Proc Calif Acad Sci 43:221-238

* Trussell GC, Matassa CM, Luttbeg B (2011) The effects of variable predation risk on foraging and growth: less risk is not necessarily better. Ecology 92:1799-1806

* Trzcinski MK, Mohn R, Bowen WD (2006) Continued decline of an Atlantic cod population: How important is gray seal predation? Ecol Appl 16:2276-2292

* Wenzel FW, Early G, Josephson E, Greer B and others (2017) What does stomach content analysis tell us about the diet of gray seals (Halichoerus grypus) incidentally caught in fisheries off the northeast United States? https://www. researchgate.net/publication/320881157_What_does_ stomach_content_analysis_tell_us_about_the_diet_of_ gray_seals_Halichoerus_grypus_atlantica_incidentally_ caught_in_fisheries_off_the_northeast_United_States

*Wirsing AJ, Heithuas MR, Frid A, Dill L (2008) Seascapes of fear: evaluating sublethal predator effects experienced and generated by marine mammals. Mar Mamm Sci 24: $1-15$

* Wood SA, Murray KT, Josephson E, Gilbert J (2020) Rates of increase in gray seal (Halichoerus grypus atlantica) pupping at recolonized sites in the United States, 1988-2019. J Mammal 101:121-128

Submitted: July 3, 2019; Accepted: April 21, 2020

Proofs received from author(s): June 18, 2020 